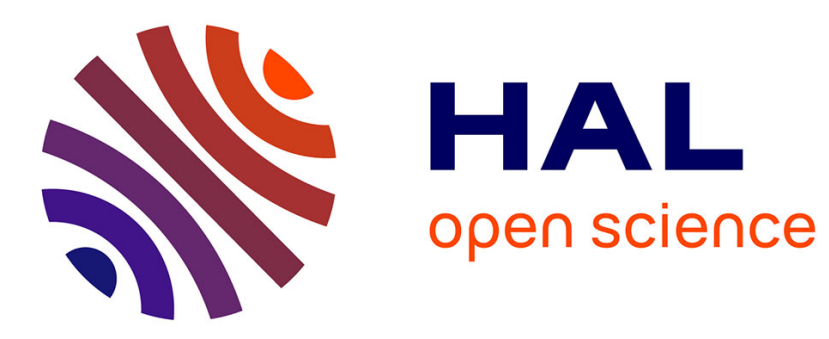

\title{
Study of Turn-to-Turn Electrical Breakdown for Superconducting Fault Current Limiter Applications
}

Raphaël Chassagnoux, Olivier Lesaint, Nelly Bonifaci, Olivier Gallot-Lavallée,

Sébastien Flury, Jean-Luc Palenzuela, Pierre Legendre, Guillaume Escamez, Christophe Creusot, Alain Girodet

\section{To cite this version:}

Raphaël Chassagnoux, Olivier Lesaint, Nelly Bonifaci, Olivier Gallot-Lavallée, Sébastien Flury, et al.. Study of Turn-to-Turn Electrical Breakdown for Superconducting Fault Current Limiter Applications. IEEE Transactions on Applied Superconductivity, In press, 29 (5), pp.1-5. 10.1109/TASC.2019.2902117 . hal-02090960

\section{HAL Id: hal-02090960 https://hal.science/hal-02090960}

Submitted on 21 May 2021

HAL is a multi-disciplinary open access archive for the deposit and dissemination of scientific research documents, whether they are published or not. The documents may come from teaching and research institutions in France or abroad, or from public or private research centers.
L'archive ouverte pluridisciplinaire HAL, est destinée au dépôt et à la diffusion de documents scientifiques de niveau recherche, publiés ou non, émanant des établissements d'enseignement et de recherche français ou étrangers, des laboratoires publics ou privés. 


\title{
Study of Turn-to-Turn Electrical Breakdown for Superconducting Fault Current Limiter Applications
}

\author{
R. Chassagnoux, O. Lesaint, N. Bonifaci, O. Gallot-Lavallée, S. Flury, J-L. Palenzuela, P. Legendre, G. Es- \\ camez, C. Creusot and A. Girodet
}

\begin{abstract}
The rational insulation design of a resistive superconducting fault current limiter (r-SCFCL) requires data gathered from experimental setups representative of the final apparatus. Therefore, an experimental study was performed to characterize the electrical breakdown (BD) of liquid nitrogen $\left(\mathrm{LN}_{2}\right)$ in the particular conditions of a quenching superconducting device. To reproduce the electrical stress occurring within a real r-SCFCL winding, BD voltages with a grounded tape electrode were investigated with different polarities and pressures, with and without transient heating on the tape electrode. Pictures obtained with a high-speed camera and breakdown delay measurements allow to further characterize breakdown mechanisms.
\end{abstract}

Index Terms - breakdown, insulation design, superconducting fault current limiters, liquid nitrogen, bubble

\section{INTRODUCTION}

$\mathbf{T}$ HE r-SCFCL is a very promising protection device for HVDC multi-terminal grids [1], [2]. For the design of a high voltage r-SCFCL, the electrical insulation is one of the key challenges to address. The electrical insulation strategy of the r-SCFCL using the $2^{\text {nd }}$ generation of superconducting tape developed in the H2020 European project FASTGRID [3], is expected to rely on $\mathrm{LN}_{2}$ as a coolant and an insulator, which is typical of high-temperature superconducting systems. Although breakdown phenomena in $\mathrm{LN}_{2}$ have been studied for a long time [4] - [6], their specificities are not all well known. In particular, the breakdown voltage of $\mathrm{LN}_{2}$ is expected to be severely reduced during a quench, due to the intense heating leading to the appearance of vapor bubbles in $\mathrm{LN}_{2}$ [7] - [9] . The experimental setup is designed to reproduce the particular thermal and insulating features of a r-SCFCL occurring during a quench. Within windings, breakdowns are likely to be triggered at the sharp edges of superconducting tapes, where a strong electric field reinforcement occurs. In this study, breakdown experiments will be carried out using a tape-plane geometry. In order to reproduce boiling and electric field conditions occurring within

\footnotetext{
Manuscript receipt and acceptance dates will Manuscript receipt and acceptance dates will be inserted here. Acknowledgment of support is placed in this paragraph as well. Consult the IEEE Editorial Style Manual for examples

R. Chassagnoux is with SuperGrid Institute SAS, 23 rue Cyprian, 69611 Villeurbanne Cedex, France, and also with Univ. Grenoble Alpes, CNRS, Grenoble INP, G2Elab, F-38000, Grenoble, France

P. Legendre, G. Escamez, C. Creusot and A. Girodet are with SuperGrid Institute SAS, 23 rue Cyprian, 69611 Villeurbanne Cedex, France

O. Lesaint, N. Bonifaci, O. Gallot-Lavallée, S. Flury and J-L. Palenzuela are with Univ. Grenoble Alpes, CNRS, Grenoble INP, G2Elab, F-38000, Grenoble, France
}

windings during a quench, a transient heating will be generated on this tape by pulsed Joule effect, while high voltage is applied on the plane electrode.

The purpose of this paper is to present several results obtained with this experimental setup. First, heating and boiling conditions of $\mathrm{LN}_{2}$ with this particular heated tape geometry will be depicted thanks to a high speed camera. BD voltage measurements will be presented as well as their variation versus heating and voltage polarity. Finally, BD delay measured with transient heating will provide additional information about prebreakdown mechanisms.

\section{EXPERIMENTAL SETUP AND METHODS}

\section{A. Experimental Setup}

The experimental setup involves a high voltage cryostat already described in previous papers [5], [7]. In this study, temperature was set to $77 \mathrm{~K}$ and pressure was controlled from 0.10 to $0.25 \mathrm{MPa}$. Thus $\mathrm{LN}_{2}$ was as the boiling point at $0.10 \mathrm{MPa}$, and subcooled (i.e. with a lower temperature than the boiling temperature) at higher pressures. The breakdown gap consists of a plane electrode $(\varnothing=40 \mathrm{~mm})$ connected to high voltage facing a grounded tape electrode (Fig. 1). The gap distance is set to $10 \mathrm{~mm}$. The dimensions of the tape $(100 \mu \mathrm{m} \times 12 \mathrm{~mm}$ cross section, $100 \mathrm{~mm}$ length) and its material (Hastelloy ${ }^{\circledR} \mathrm{C} 276$ ) are chosen to be close to a real superconducting tape. This tape has a resistance of about $0.10 \Omega$, and can be heated by Joule effect with a pulsed current source configured to raise its temperature from $77 \mathrm{~K}$ to $400 \mathrm{~K}$ in about $40 \mathrm{~ms}$. These parameters are relevant of the conditions actually found in a real r-SCFCL during a quench.

This work was supported by a grant overseen by the French National Research Agency (ANR) as part of the "Investissements d'Avenir" Program (ANE-ITE002-01)

This project has received funding from the European Union's Horizon 2020 research and innovative programme under grant agreement No 721019.

Color versions of one or more of the figures in this paper are available online at http://ieeexplore.ieee.org.

Digital Object Identifier will be inserted here upon acceptance. 


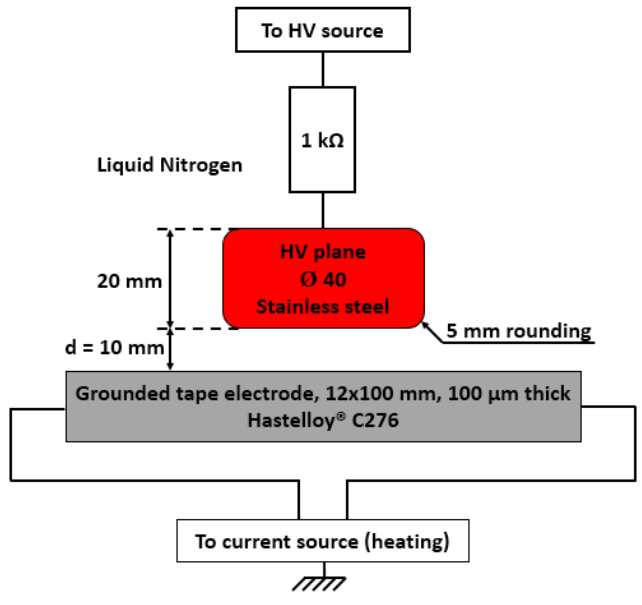

Fig. 1. Detailed schematic view of the electrode setup. The tape edge faces the plane (perpendicular configuration).

\section{B. Methodology}

High voltage tests were performed according to the IEC 60060-1 standard, annex A. It classifies high voltage experiments into three classes, the two following being used in these experiments:

\section{1) Up-and-down tests}

Up-and-down tests were performed with a constant DC voltage superimposed with a transient tape heating. The high voltage was ramped up and maintained for $10 \mathrm{~s}$, then the transient heating was applied and the voltage maintained again for another $10 \mathrm{~s}$, which was enough to let all bubbles leave the inter-electrode space. The procedure was set to provide the $10 \%$ breakdown probability voltage ( $\left.\mathrm{V}_{\mathrm{BD} \_10 \%}\right)$ according to the IEC 60060-1 standard (although this standard does not apply to transient thermal stress tests, but only to transient voltage stress tests). The voltage target is decreased if a BD occurs in a series of 7 voltage applications, otherwise it is increased by the same amount. This procedure was repeated until 20 series were accepted, resulting in about 100 voltage applications for each experimental condition.

\section{2) Progressive stress tests}

Progressive stress tests were performed with high voltage DC ramps, without transient tape heating. The slope of ramps was set to $1 \mathrm{kV} / \mathrm{s}$. This procedure was repeated 20 times for each experimental condition.

To provide a common framework to BD voltage in spite of the diversified protocols, Weibull statistics [10], [11] were used to compute the $10 \% \mathrm{BD}$ probability voltage, for both Up-anddown and Progressive stress tests. The choice of the $10 \% \mathrm{BD}$ probability procedure was made to get closer to a real apparatus insulation conditions (which is expected to be reliable, therefore with a very low BD probability) compared to a more standard $50 \%$ BD probability approach.

The waiting time between two consecutive tests is at least 1 minute. In this paper, the polarity quoted for pre-breakdown and breakdown events corresponds to the polarity of the

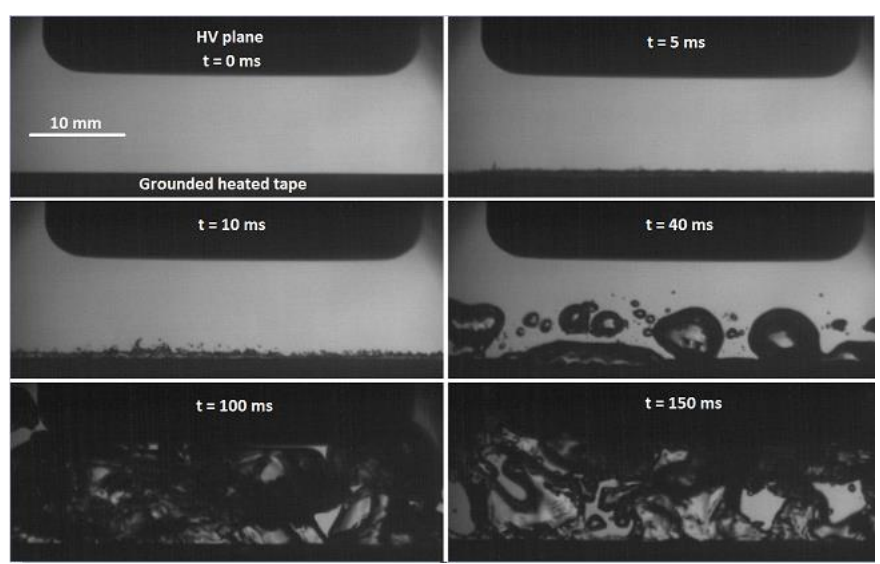

Fig. 2. Camera recording of the boiling of $\mathbf{L N}_{2}$ along the heated tape at different instants at $0.10 \mathrm{MPa}$, without high voltage applied. The transient heating starts at $\mathrm{t}=0 \mathrm{~ms}$ and stops at $\mathrm{t}=40 \mathrm{~ms}$.

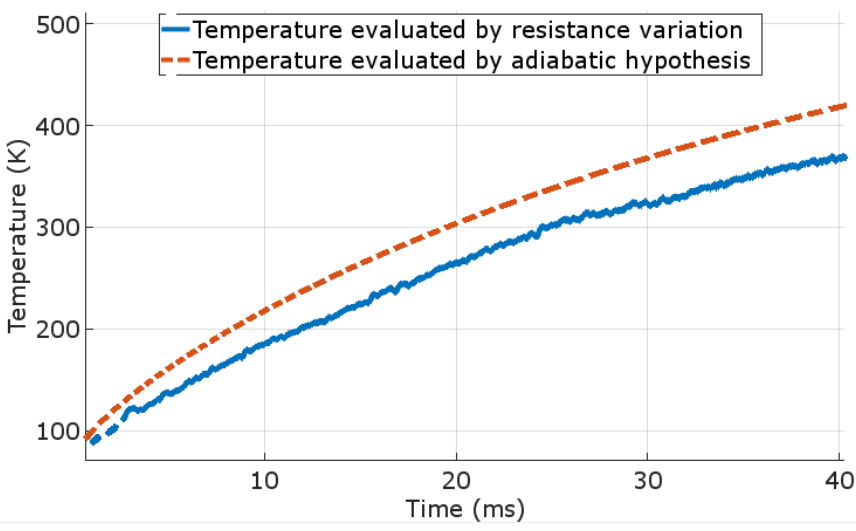

Fig. 3. Experimental temperature evaluation of the tape by resistance variation and by adiabatic hypothesis. The first two milliseconds of the 'resistance variation' curve are not accurate due to parasitic inductive effects.

grounded tape electrode, where a large electric field reinforcement occurs.

\section{Heating Characteristics}

A typical recording of the transient boiling induced by the pulsed heating at $0.10 \mathrm{MPa}$ is presented in Fig. 2. The total electrical energy injected in the tape through Joule effect during the transient heating is about $100 \mathrm{~J}$, corresponding to a mean current of $160 \mathrm{~A}$ and a mean power of $2.5 \mathrm{~kW}$ dissipated during the $40 \mathrm{~ms}$ current pulse. The voltage applied on the tape is monitored with a Kelvin 4-wire measurement system, and the current is recorded via a $10 \mathrm{~m} \Omega$ shunt. From the current and voltage, two indirect measurements of the tape temperature were compared:

1) The average tape temperature was deduced from the measured resistance increase during the pulse [12].

2) Assuming that no thermal exchanges occurs with the surrounding $\mathrm{LN}_{2}$ (adiabatic hypothesis), the tape temperature was calculated from the measured dissipated energy and the specific heat of Hastelloy ${ }^{\circledR}$ C276 [12].

A typical plot of calculated temperatures is shown in Fig. 3. The temperature computed through adiabatic hypothesis is higher, which is logical since it neglects the heat flowing out of 
the tape. A more realistic temperature evaluation is provided by the resistance variation method.

Fig. 2 shows that the generation of vapor bubbles at $0.10 \mathrm{MPa}$ becomes visible after a few milliseconds, and continues for a long time after the heating current has been switched off. At about $100 \mathrm{~ms}$, vapor bubbles totally bridge the gap between electrodes.

\section{STUDY OF BREAKDOWN}

\section{A. Breakdown at the boiling point $(77 \mathrm{~K}, 0.10 \mathrm{MPa})$}

Breakdown voltage were first measured at atmospheric pressure, in order to investigate the influence of transient heating and voltage polarity. Fig. 4 shows the $\mathrm{V}_{\mathrm{BD} \_} 10 \%$ values and their confidence intervals for each experimental conditions.

Without heating, breakdown is recorded at higher voltage with the positive tape electrode. Pre-breakdown streamers in $\mathrm{LN}_{2}$ are indeed known to be initiated at a slightly higher voltage in positive polarity compared to negative polarity [13]. These results are consistent with a "initiation-controlled" breakdown process (i.e. when every pre-breakdown streamer propagates to breakdown). Moreover, positive BD voltages depicted in Fig. 4 are significantly higher than those obtained in the literature in needle-plane configuration, with identical gap distance [4], [13]. This can be explained by the lower electric field enhancement occurring at tape edges due to their geometrical 2D invariance, compared to needle tips. Computations with a FEM software provides an utilization factor (mean electric field divided by max. electric field) of 0.046 in this experiment, whereas most needle-plane configuration have an utilization factor lying between $10^{-4}$ and $10^{-2}$.

Transient heating has a dramatic impact on $\mathrm{V}_{\mathrm{BD} \_10 \%}$ at the $\mathrm{LN}_{2}$ boiling point $(77 \mathrm{~K}, 0.10 \mathrm{MPa})$. It reduces the $\mathrm{BD}$ voltage from $106 \mathrm{kV}$ down to $23 \mathrm{kV}$ for positive tape, and from $88 \mathrm{kV}$ to $10.7 \mathrm{kV}$ for negative tape. These reductions ratios (from 5 to 8 ) are significantly higher than those observed in previous studies (reduction ratios from 2 to 3 with continuous and transient heating [8], [9]). This discrepancy is probably due to the different electrode geometry used (sphere/plane gaps were used in many previous papers). The heating conditions are also significantly different, with a much larger heating power and energy used in our experiment. At the boiling point, pulsed heating induces a huge amount of nitrogen vapor rapidly spanning across the gap, to form "bridges", even when no voltage is applied (Fig. 2). Discharges occurring in the vapor phase must be considered to explain BD phenomena in such conditions [14].

\section{B. Influence of Pressure with Transient Heating}

Pressure was increased and controlled from 0.10 MPa to $0.25 \mathrm{MPa}$ by steps of $0.05 \mathrm{MPa}$, while applying the same transient heating as in Fig. 4. A summary of these results is pictured on Fig. 5.

In both polarities, the BD voltage increases rapidly as the pressure increases. It is especially remarkable with the negative tape polarity, for which the $\mathrm{V}_{\mathrm{BD}_{-} 10 \%}$ grows from $11 \mathrm{kV}$ at $0.10 \mathrm{MPa}$ to $98 \mathrm{kV}$ at $0.25 \mathrm{MPa}$.

The origin of this favorable effect results from the combined influence of pressure on boiling $\left(\mathrm{LN}_{2}\right.$ at $77 \mathrm{~K}$ is not any more at the boiling point above $0.10 \mathrm{MPa}$ ), and on the vapor density within bubbles. At $77 \mathrm{~K}$ with pressure beyond $0.10 \mathrm{MPa}$, any occurring vapor bubble will rapidly condensate and collapse. The dynamics of observed vapor bubbles therefore result from a competition between heating (that produces vapor) and condensation. Bridging the gap with $\mathrm{N}_{2}$ bubbles would require much more thermal energy compared to $\mathrm{LN}_{2}$ at the boiling point. With fixed thermal energy, the increase of pressure leads

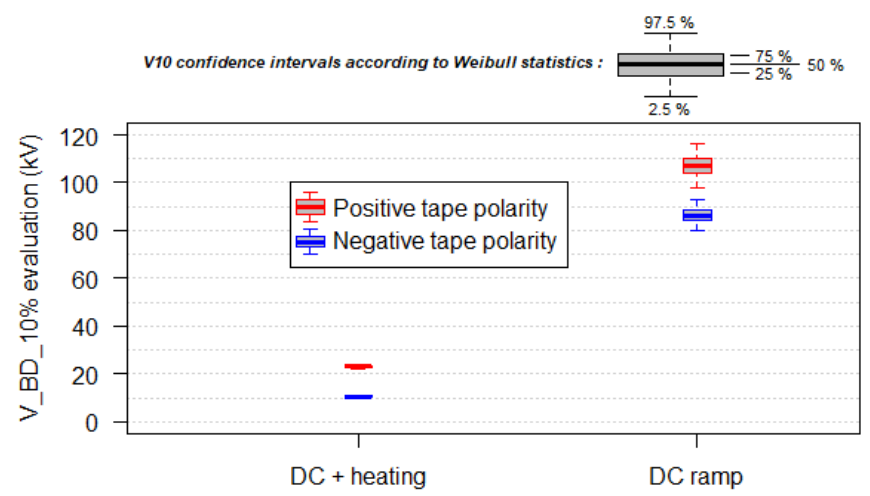

Fig. 4. $\mathrm{V}_{\mathrm{BD} \_10 \%}$ at $0.10 \mathrm{MPa}$ with transient heating ("DC + heating", with Up-and-down tests) and without transient heating ("DC ramp", with Progressive stress tests).

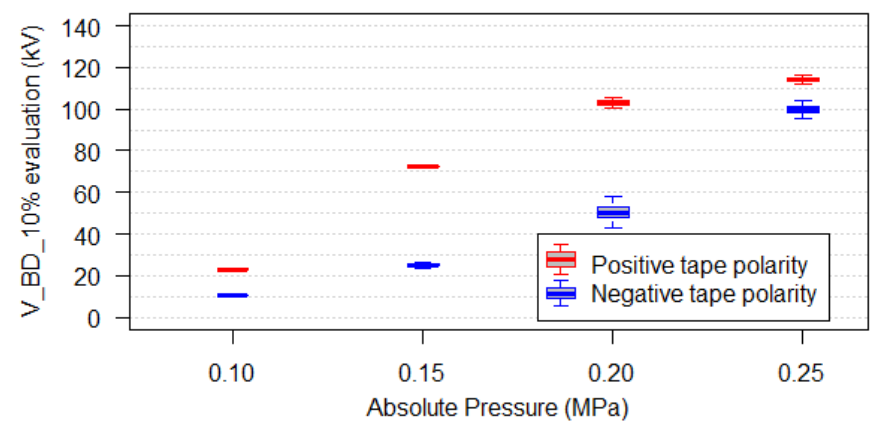

Fig. 5. $\mathrm{V}_{\mathrm{BD}} 10 \%$ with transient heating ("Up-and-down tests") between $0.10 \mathrm{MPa}$ and $0.25 \mathrm{MPa}$ for both tape polarities. Confidence intervals are plotted in the same way as in Fig. 4.

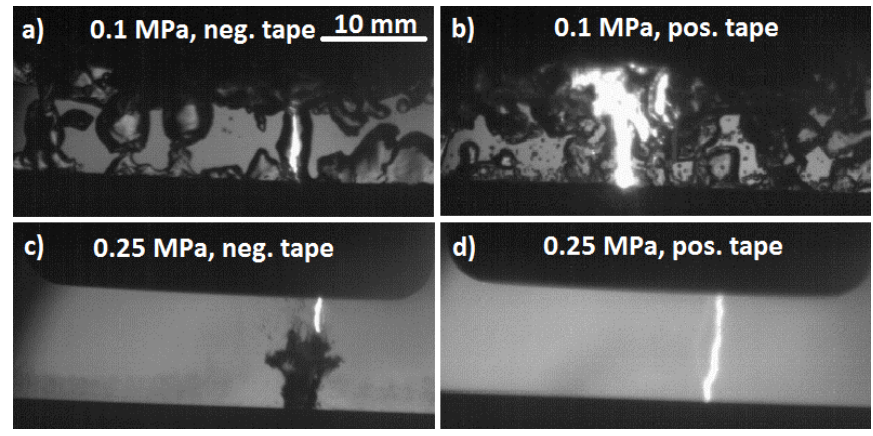

Fig. 6. Picture of typical BD with transient heating for different polarities and pressures. For all pictures, the applied constant DC voltage level is close to the respective $\mathrm{V}_{\mathrm{BD}_{-} 10 \%}$ shown in Fig.5. (a) $\mathrm{BD}$ at $0.10 \mathrm{MPa}$ and negative tape polarity, occurring in a full gaseous bridge. (b) $\mathrm{BD}$ at $0.10 \mathrm{MPa}$ and positive tape polarity, occurring in a full gaseous bridge. (c) BD at $0.25 \mathrm{MPa}$ and negative tape polarity, occurring in a partial gaseous bridge. (d) $\mathrm{BD}$ at $0.25 \mathrm{MPa}$ and positive tape polarity, occurring mainly in $\mathrm{LN}_{2}$. 
to the reduction of bubble volume, and also to the increase of the vapor density. With the available thermal energy used here, and with no applied electric field, vapor bubbles bridging the whole gap such as on Fig. 2 are not any more observed with pressure beyond $0.20 \mathrm{MPa}$. This shows that breakdown processes different from a simple gaseous discharge across a vapor bridge are involved when pressure is raised.

Fig. 6 presents typical breakdown photographs taken for both polarities in at the boiling point $(0.10 \mathrm{MPa})$, and at $0.25 \mathrm{MPa}$. At $0.10 \mathrm{MPa}$ with both polarities, breakdown occurs within the gaseous bridge induced by the pulsed heating. Breakdown voltages in negative polarity are about half those measured in positive polarity.

At $0.25 \mathrm{MPa}$ in negative polarity, BD occurs within a vapor phase that partially bridges the gap, and with a rather irregular shape compared to bubbles observed at $0.10 \mathrm{MPa}$. Bubbles driven by buoyancy only (no electric field applied) travels at about $0.2 \mathrm{~m} / \mathrm{s}$, whereas the velocity of these pre-breakdown "bubbles" ranges from 2 to $5 \mathrm{~m} / \mathrm{s}$. Since this vapor cavity does not exists without applied voltage, it is clear that its development is assisted by the electric field. Bubble extension assisted by electric field and leading to breakdown can be ascribed to the propagation of slow " 1 st mode" streamer in liquids [15],
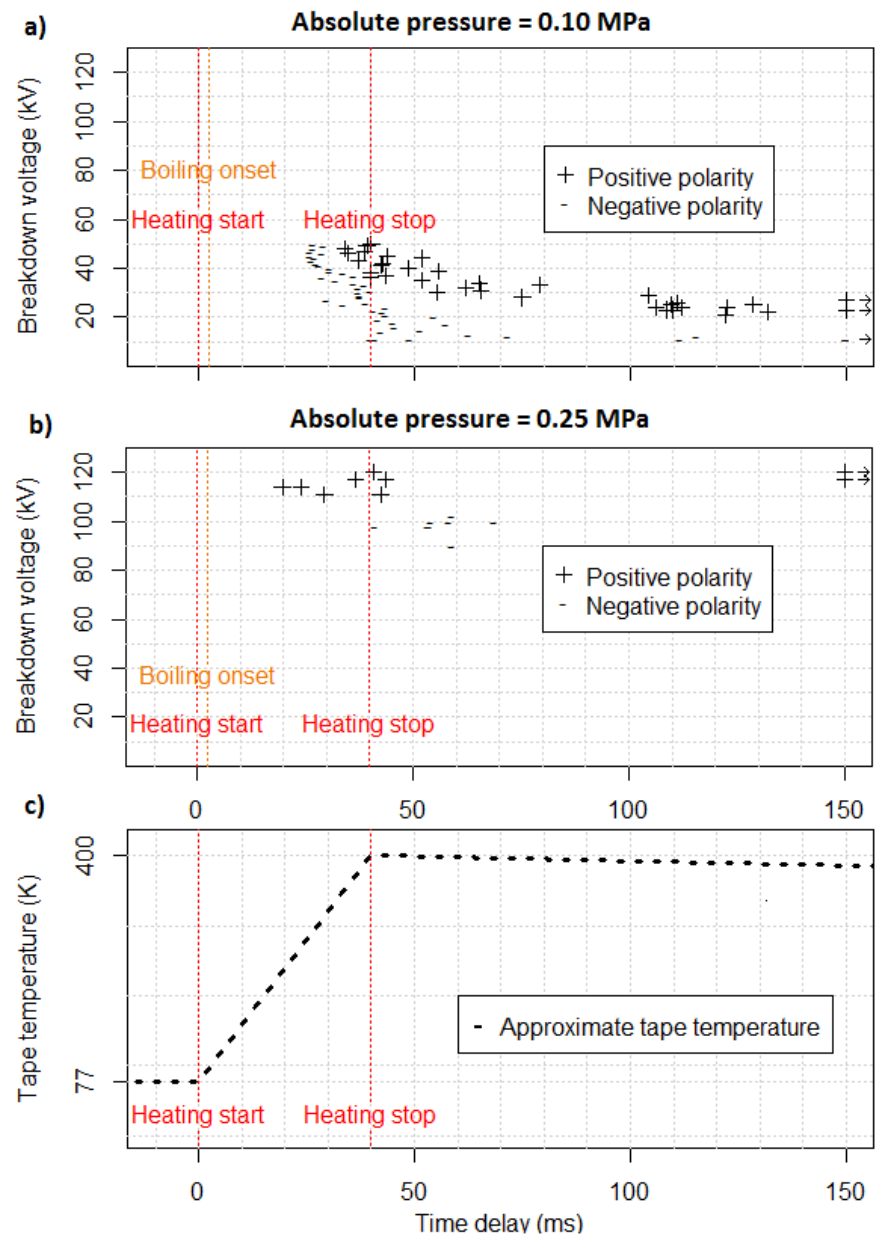

Fig. 7. Comparison of heating timeline and BD delay. (a) Breakdown voltage vs. breakdown delay, DC with transient heating at $0.10 \mathrm{MPa}$. (b) Breakdown voltage vs. breakdown delay, DC with transient heating at $0.25 \mathrm{MPa}$. (c) Approximate tape temperature profile over time (independent of temperature). which velocity may be as low as few $\mathrm{m} / \mathrm{s}$. It is supposed that both the energy dissipation due to internal partial discharges, and the influence of electrostatic pressure at the gas/liquid boundary contribute to the extension of the gas phase of " 1 st mode" streamers [15]. From shot to shot, its development is also much more unstable as compared to bubbles at $0.10 \mathrm{MPa}$. At a voltage corresponding to $10 \% \mathrm{BD}$ probability, $1^{\text {st }}$ mode streamers generally collapses after few ms without BD.

At $0.25 \mathrm{MPa}$ with positive polarity, only sub-millimeter bubbles can be seen on the tape prior to BD. As in point-plane gaps, breakdown results from the fast propagation of filamentary streamers (velocity $>1 \mathrm{~km} / \mathrm{s}$ ) [15]. Positive BD appears earlier than negative ones: at $0.20 \mathrm{MPa}$ some of them are triggered as soon as the boiling starts (around $2.5 \mathrm{~ms}$ after onset of the heating pulse). With both polarities, it is clear that the initiation of streamers is induced by the pulsed heating. Contrary to the case of boiling conditions $(0.10 \mathrm{MPa})$, the role of pulsed heating seems mainly limited to helping streamer initiation.

At any pressure, the negative polarity shows the weakest BD voltage and must be taken into account for insulation design. This is in contradiction with the general observation that positive streamers constitute the most dangerous pre-breakdown phenomena for high voltage applications in usual conditions. This certainly results from the fact that the liquid remains quite close to boiling conditions in our experiments. Even when pressure is increased to $0.25 \mathrm{MPa}$, the difference between ambient temperature $(77 \mathrm{~K})$ and boiling temperature $(86 \mathrm{~K})$ remains small compared to usual insulating liquids at room temperature, used far from boiling conditions.

\section{Breakdown Delay with Transient Heating}

When breakdown occurred in the previously described experiments, the delay between the heating start and breakdown (detected by light emission) was recorded. Results at the boiling point $(77 \mathrm{~K}, 0.10 \mathrm{MPa})$ and in subcooled conditions $(77 \mathrm{~K}$, $0.25 \mathrm{MPa}$ ) with both tape polarities are summarized in Fig. 7 . At the boiling point, BD occurs within a gaseous bridge (Fig. 6). Breakdown did not immediately follow the onset of boiling, and occurred rather after a large delay (from 25 to $150 \mathrm{~ms}$ ), when the gaseous bridge is fully established. This occurred either slightly before the end of heating (at $40 \mathrm{~ms}$ ), or some tens of ms after. Within the delay range observed, the tape temperature remained almost constant after the end of transient heating. Shorter delays were recorded at higher voltage, and some decrease of the breakdown voltage was observed versus time.

A similar behavior was already recorded in [16]. Hayakawa et al. observed that under transient thermal stress with constant AC voltage applied, breakdown induced by heating and subsequent boiling (called "Dynamic BD") occurred mainly after 100 to $200 \mathrm{~ms}$. This long time delay includes the minimum time required for bubbles to be generated, grow, and bridge the gap, and also additional delays linked to the gas discharge process. The onset of the gas discharge may also involve the gas temperature rise until a critical level (thus reducing the gas density 
and hence favoring gas breakdown), as well as statistical time (availability of an electron able to trigger the breakdown process). Nevertheless, differences probably exist between prebreakdown processes in AC and DC. Contrarily to DC, charge injection in bubbles may go back and forth in AC because of the long BD delay in the range of tens of milliseconds. Bubble deformation due to electrohydrodynamic processes is also much stronger in DC compared to $\mathrm{AC}$, increasing the risk of a gaseous bridge formation.

\section{CONCLUSION}

In this paper, pre-breakdown and breakdown phenomena were studied under DC voltage in a tape-plane geometry. The tape can be transiently heated, in order to simulating the case of a quenching superconducting tape. The results show a significant impact of both polarity and transient heating.

At the boiling point $(77 \mathrm{~K}, 0.10 \mathrm{MPa})$ transient heating induces gaseous bridges which decrease drastically the breakdown voltage. Breakdown results essentially from a gaseous discharge process occurring within vapor bridges. Long breakdown delays are associated with the slow extension of vapor bubbles across the gap.

The application of a hydrostatic pressure up to $0.25 \mathrm{MPa}$ has a strong positive influence on BD voltage. Without applied high voltage, gaseous bridge development is impeded. With negative polarity, a "field-assisted" vapor bridge development, reminiscent to the streamer process in liquids induces breakdown. These slow " 1 st mode" streamers lead to the lowest breakdown voltages. Such values provide guidelines for the design of practical r-SCFCL insulation. In positive polarity, breakdown results from faster filamentary streamers.

Future works will include similar studies in the same experimental conditions at $65 \mathrm{~K}$ instead of $77 \mathrm{~K}$, in order to investigate the influence of different subcooling conditions.

\section{REFERENCES}

[1] J. Bock, A. Hobl, J. Schramm, S. Kramer and C. Janke, "Resistive Superconducting Fault Current Limiters Are Becoming a Mature Technology," IEEE Transactions on Applied Superconductivity, vol. 25, pp. 1-4, jun 2015.

[2] P. Tixador and A. Badel, "Superconducting Fault Current Limiter optimized design," Physica C: Superconductivity and its Applications, vol. 518, pp. 130-133, Nov 2015.

[3] "FASTGRID," [Online]. Available: https://www.fastgrid-h2020.eu/.

[4] J. Fleszyński, A. Zelek and J. I. Skowroński, "Development of discharges in liquid nitrogen in nonuniform electrical field," Journal of Electrostatics, vol. 7, pp. 39-46, aug 1979.

[5] P. E. Frayssines, O. Lesaint, N. Bonifaci, A. Denat and F. Devaux, "Prebreakdown and breakdown phenomena under uniform field in liquid nitrogen and comparison with mineral oil," IEEE Transactions on Dielectrics and Electrical Insulation, vol. 10, pp. 970-976, dec 2003.

[6] S. Fink, R. Mueller, M. Noe, V. Zwecker and H.-R. Kim, "Withstand alternating voltage of liquid nitrogen in the presence of gas bubbles," in 2014 IEEE 18th International Conference on Dielectric Liquids (ICDL), 2014.

[7] T. P. Hong, P.-E. Frayssines, O. Lesaint, F. Aitken and F. Devaux, "Influence of vapor bubbles initiated by steady heating on the breakdown of liquid nitrogen," CEIDP, pp. 313-316, October 2003.

[8] N. Hayakawa, K. Ishida, M. Mimbu, H. Kojima, S. Isojima and M. Kuwata, "Volume Effect of Dynamic Breakdown Strength in LN2 for Insulation Design of Resistive Superconducting Fault Current Limiters," IEEE Transactions on Applied Superconductivity, vol. 28, no. 4, 2018.

[9] I. Sauers, R. James, A. Ellis, E. Tuncer, G. Polizos and Marshall Pace, "Effect of Bubbles on Liquid Nitrogen Breakdown in Plane-Plane Electrode Geometry From 100-250 kPa", IEEE Transactions on Applied Superconductivity, vol. 21, no. 3, June 2018

[10] H. Goshima, N. Hayakawa, M. Hikita, H. Okubo and K. Uchida, "Weibull statistical analysis of area and volume effects on the breakdown strength in liquid nitrogen," IEEE Transactions on Dielectrics and Electrical Insulation, vol. 2, pp. 385-393, jun 1995.

[11] J. Gerhold, M. Hubmann and E. Telser, "Breakdown probability and size effect in liquid helium," IEEE Transactions on Dielectrics and Electrical Insulation, vol. 5, pp. 321-333, jun 1998.

[12] J. Lu, E. S. Choi and H. D. Zhou, "Physical properties of Hastelloy C-276 at cryogenic temperatures," Journal of Applied Physics, vol. 103, 2008.

[13] P.-E. Frayssines, "Etude des propriétés diélectriques de l'azote liquide sous haute tension et caractérisation des streamers positifs par spectroscopie d'émission," Université Joseph Fourier, Grenoble 1, PhD Thesis, 2002.

[14] N. Hill and M. Kurrat, "Discharge Mechanisms in Liquid Nitrogen-Breakdown Field Strength of Gaseous Nitrogen," IEEE Transactions on Applied Superconductivity, vol. 28, 2018.

[15] O. Lesaint, "Prebreakdown phenomena in liquids: propagation 'modes' and basic physical properties," Journal of Physics D: Applied Physics, vol. 49, no. 14, mar 2016.

[16] N. Hayakawa, T. Matsuoka, H. Kojima, S. Isojima and M. Kuwata, "Breakdown Characteristics and Mechanisms of Liquid Nitrogen Under Transient Thermal Stress for Superconducting Fault Current Limiters," IEEE Transactions on Applied Superconductivity, vol. 27, pp. 1-5, jun 2017 